\title{
Participation of the cholinergic system in the ethanol-induced suppression of paradoxical sleep in rats
}

\author{
L.A. Papale, M.L. Andersen, J.C. Perry and S. Tufik \\ Departamento de Psicobiologia, Escola Paulista de Medicina, Universidade Federal de São Paulo, \\ São Paulo, SP, Brasil
}

Correspondence to: M.L. Andersen, Departamento de Psicobiologia, EPM, UNIFESP, Rua Napoleão de Barros, 925, 04024-002 São Paulo, SP, Brasil

Fax: +55-11-5572-5092. E-mail: mandersen@psicobio.epm.br

\begin{abstract}
Sleep disturbance is among the many consequences of ethanol abuse in both humans and rodents. Ethanol consumption can reduce REM or paradoxical sleep (PS) in humans and rats, respectively. The first aim of this study was to develop an animal model of ethanol-induced PS suppression. This model administered intragastrically (by gavage) to male Wistar rats ( 3 months old, $200-250 \mathrm{~g}$ ) 0.5 to $3.5 \mathrm{~g} / \mathrm{kg}$ ethanol. The $3.5 \mathrm{~g} / \mathrm{kg}$ dose of ethanol suppressed the PS stage compared with the vehicle group (distilled water) during the first 2-h interval $(0-2 \mathrm{~h} ; 1.3$ vs $10.2 ; \mathrm{P}<0.001)$. The second aim of this study was to investigate the mechanisms by which ethanol suppresses PS. We examined the effects of cholinergic drug pretreatment. The cholinergic system was chosen because of the involvement of cholinergic neurotransmitters in regulating the sleep-wake cycle. A second set of animals was pretreated with 2.5, 5.0, and $10 \mathrm{mg} / \mathrm{kg}$ pilocarpine (cholinergic agonist) or atropine (cholinergic antagonist). These drugs were administered $1 \mathrm{~h}$ prior to ethanol $(3.5 \mathrm{~g} / \mathrm{kg})$ or vehicle. Treatment with atropine prior to vehicle or ethanol produced a statistically significant decrease in PS, whereas pilocarpine had no effect on minutes of PS. Although the mechanism by which ethanol induces PS suppression is not fully understood, these data suggest that the cholinergic system is not the only system involved in this interaction.
\end{abstract}

Key words: Cholinergic; Atropine; Pilocarpine; Ethanol; Paradoxical sleep; Electroencephalography

Research supported by Associação Fundo de Incentivo à Psicofarmacologia (AFIP) and FAPESP (CEPID \#98/14303-3 to S. Tufik and \#04/04008-7 to J.C. Perry). L.A. Papale was the recipient of a PIBIC fellowship from CNPq (\#1069/04). M.L. Andersen and $\mathrm{S}$. Tufik are recipients of scientific productivity fellowships from CNPq.

Received May 28, 2007. Accepted August 20, 2008

\section{Introduction}

Ethanol has been documented to impair sleep quality by causing sleep disturbances such as snoring and insomnia (1-3). Studies of ethanol administration and its relationship to sleep in experimental animals have demonstrated changes quite similar to those seen in humans. Acute ethanol administration has been shown to reduce sleep latency (4) and increase the percentage of slow wave sleep (SWS; 5). Indeed, SWS was increased at doses of 0.5 and $1.5 \mathrm{~g} / \mathrm{kg}$, whereas paradoxical sleep (PS) was decreased during the first $6 \mathrm{~h}$ after $1.5 \mathrm{~g} / \mathrm{kg}$ (5). In addition to the significant impairment in the duration of PS, ethanol has a dosedependent effect on the sleep of rats; as the administration of this substance increases, the percentage of PS significantly decreases $(6,7)$. Based on the literature, the development of an animal model of ethanol-induced PS suppression is extremely important to better understand the neural mechanisms underlying the effects of ethanol on sleep. Furthermore, this animal model should provide a tool to better understand the mechanism by which ethanol can selectively impair this particular stage of sleep. Therefore, the first aim of the present study was to introduce and validate an animal model of ethanol-induced PS suppression. 
The consistent effects that ethanol has on PS can be due to its interaction with several neurotransmitters in the central nervous system that have the capacity to impair attention, memory, and executive functions in addition to sleep regulation. Moreover, PS may be mediated by the effect that ethanol has on either the steady-state levels or turnover rates of one or more neurotransmitters.

Several studies during the past three decades have shown an important role in sleep modulation for monoaminergic and cholinergic neurons located in the pontine brainstem. Moreover, acetylcholine is a well-known neurotransmitter involved in various fundamental central functions such as synchronization of the circadian cycle and sleep-waking control (8). There is considerable evidence indicating that the final effector mechanism responsible for PS generation resides in the pontine reticular formation (9). Moreover, pharmacological and neuroanatomical studies indicate that the PS switch-on mechanism may be mediated by the cholinergic system (10). For instance, microinjections of cholinergic agonists into the medial pontine reticular formation readily trigger PS, whereas injections just outside this zone are ineffective (11). A muscarinic agonist (pilocarpine) was shown to both enhance the processes of cortical activation of waking and shorten the latency of PS $(12,13)$. Ethanol also inhibits acetylcholine release and increases central acetylcholine levels in rat cortical slices $(14,15)$, thereby antagonizing the effects of ethanol. In addition, atropine (a cholinergic antagonist) in doses greater than $3 \mathrm{mg} / \mathrm{kg}$ prevents physostigmine antagonism mediated by ethanol (13). Although many studies have suggested a reciprocal interaction between the cholinergic system and the generation of PS, it remains difficult to relate the theoretical framework of this model and the pharmacological data with the fact that selective lesions of either cholinergic or monoaminergic nuclei in the brainstem have relatively limited effects on PS. Thus, the second aim of this study was to investigate the possible role of the cholinergic system in the generation of PS in our model of ethanol-induced PS suppression.

In the present study, we describe an animal model of ethanol-induced PS suppression and provide data related to the cholinergic system and the generation of PS. Since ethanol significantly decreases PS, we hypothesized that the administration of cholinergic drugs will reverse PS suppression.

\section{Subjects and Methods}

\section{Subjects}

Male Wistar rats were bred and raised in the animal facility of the Department of Psychobiology, Universidade
Federal de São Paulo. The animals were housed in a colony maintained at $22 \pm 2^{\circ} \mathrm{C}$ with a $12: 12$-h light-dark cycle (lights on at 7:00 am) and allowed free access to food and water inside standard polypropylene cages (31 x $34 \mathrm{x}$ $31 \mathrm{~cm}$ ). Rats used in this study were maintained and treated in accordance with the guidelines established by the Ethical and Practical Principles of the Use of Laboratory Animals (16). All experimental procedures were approved by the Ethics Committee of the Universidade Federal de São Paulo (CEP \#1070/04).

\section{Surgical preparation}

The rats received ketamine hydrochloride and diazepam anesthesia (80 and $4.5 \mathrm{mg} / \mathrm{kg}$ of body weight, ip). To record cortical electrocorticogram (ECoG) with a minimum of theta activity, one pair of screw electrodes was placed through the skull: $1 \mathrm{~mm}$ posterior to bregma, $3 \mathrm{~mm}$ right to the central suture, and $1 \mathrm{~mm}$ anterior to lambda, $4 \mathrm{~mm}$ right to the central suture. To ensure the best recording of theta activity, two screw electrodes were placed in a more medial posterior position: $3 \mathrm{~mm}$ anterior to bregma, $1 \mathrm{~mm}$ left to the central suture, and $4 \mathrm{~mm}$ anterior to lambda, $1 \mathrm{~mm}$ left to the central suture. Electromyogram (EMG) electrodes were implanted in the neck muscles, soldered to a 6-pin socket, and covered with dental acrylic cement. After surgery, the rats were placed individually in round transparent plastic cages and had a 14-day surgery recovery period of 10 days without the recording cable followed by a 4-day adaptation period with the polysomnography cable connected.

\section{Electrocorticogram recording and parameters}

The animals remained in their home cages inside a Faraday chamber in a soundproof room throughout the experiment. Food and water were provided ad libitum. The recordings were performed on a Nihon Koden Co. (Japan) model QP 223-A apparatus using three channels for each animal: two for ECoG and one for neck muscle EMG. The EcoG signals were amplified and filtered with a low pass at $0.1 \mathrm{~s}(1.6 \mathrm{~Hz})$, and EMG activity was filtered with a low pass at $0.03 \mathrm{~s}(5.3 \mathrm{~Hz})$. The recording equipment was placed in an adjacent room. Throughout the recording sessions, the rats were observed through a one-way glass window. The ECoG traces were scored manually and blindly for $30 \mathrm{~s}$ epochs. The sleep stages of wakefulness, SWS, and PS were identified and scored according to a combination of ECoG, EMG, and behavioral criteria $(17,18)$. Briefly, during periods of wakefulness, rats were standing, grooming, scratching, moving around the cage, drinking or eating, or lying down with occasional movements and eyelids open paying attention to the environment. The ECoG trace for these behaviors shows low amplitude theta waves accom- 
panied by high-amplitude EMG activity. SWS episodes were characterized by a typical immobile posture with closed eyelids. The ECoG features were low-frequency, high-amplitude delta waves with occasional periods of spindles activity occurring at higher frequencies. The EMG was characterized by a reduction in muscle tone. The sleep posture during PS was similar to that in SWS, but the head was fully relaxed and there were twitches of the ears, whiskers, and distal limbs. Breathing was frequent and irregular, and the ECoG trace displayed low amplitude and high frequency with theta waves. The EMG showed an absence of muscle activity except for occasional twitches.

The following sleep parameters were considered: sleep efficiency (total sleep time during the recording time), sleep latency (time lag between the onset of recording and the first sleep period), sleep onset (time at which the animal presented cortical synchronization during five consecutive scoring epochs), PS latency (time lag between the first sleep period and the first episode of PS), SWS (time of all periods of deep sleep throughout the recording), and PS (duration of all periods of PS throughout the recording period).

\section{Animal model of ethanol-induced PS suppression}

It is known that ethanol is metabolized relatively quickly (19). Although we have recorded for $12 \mathrm{~h}$ after ethanol administration, we speculate that changes in the sleep architecture occur in the first hours of the ECoG recording as ethanol is metabolized. To assess the effects of acute intragastric ethanol administration on sleep in rats, we performed the experiment at 7 am with ECoG data collection every hour for the first $4 \mathrm{~h}$ and every $2 \mathrm{~h}$ thereafter. To provide more comprehensive figures, we elected to depict 7:00-13:00 $h$ as 0-6 $h$, and 13:00-19:00 $h$ as 6-12 $h$ after ethanol administration.

Relationship between cholinergic drugs in the animal model of ethanol-induced PS suppression

The cholinergic drugs are related to the presence of the PS stage. We designed this experiment to determine whether a cholinergic drug can induce PS in this rat model of ethanol-induced PS suppression. The cholinergic drugs pilocarpine and atropine were administered subcutaneously $1 \mathrm{~h}$ prior to the administration of ethanol. The ECoG recording was obtained throughout the same time as the induction of the PS suppression by ethanol administration. The recording sessions were performed for $12 \mathrm{~h}$.

\section{Experimental protocols}

Experiment 1. Effect of acute ethanol administration on sleep pattern. The animals were assigned to one of six groups consisting of 8 to 12 animals each. The treatment consisted of intragastric administration (gavage) of ethanol solution or vehicle. The ethanol solution was $50 \%$ ethanol $\mathrm{v} / \mathrm{v}$. On the experimental day, each group received one of the five doses of ethanol: $0.5,1.0,2.0,3.0,3.5 \mathrm{~g} / \mathrm{kg}$, and one group received $2.0 \mathrm{~mL}$ distilled water. The sleep of the animals was recorded during the 12-h light period (7:00-19:00 h).

Experiment 2. Effects of cholinergic drugs on sleep in rats with suppression of $P S$. Seventy-two rats were allocated into agonist and antagonist groups receiving pilocarpine and atropine, respectively. On the experimental day, each rat received one of three doses of pilocarpine or atropine $(2.5,5.0,10 \mathrm{mg} / \mathrm{kg})$ subcutaneously $1 \mathrm{~h}$ prior to the light period $(6: 00 \mathrm{am})$. After $1 \mathrm{~h}(7: 00 \mathrm{am})$, rats were given ethanol $(3.5 \mathrm{~g} / \mathrm{kg})$ or distilled water $(2.0 \mathrm{~mL})$ and were immediately submitted to ECoG recording. We elected to use the dose of $3.5 \mathrm{~g} / \mathrm{kg}$ ethanol that suppressed PS and altered latency to PS (see Results).

\section{Statistical analysis}

Data are reported as the mean \pm standard error of the mean (SEM). Homogeneity of variance was assessed by the Bartlett test and normal distribution of the data by the Kolmogorov-Smirnov test. Factorial analysis of variance (ANOVA) was used to assess the data of sleep and PS latencies (pilocarpine and atropine). One-way and twoway ANOVA was used to analyze ethanol data and threeway ANOVA to analyze group differences (ethanol $x$ vehicle), cholinergic treatment (pilocarpine/atropine $x$ doses), recording periods after ethanol administration (0-6- and 612-h intervals), and interaction among these three factors. The Tukey post hoc test was used to compare values of different times of sleep intervals between groups. When the Bartlett test showed absence of homoscedasticity, data were square root transformed. $\mathrm{P}<0.05$ was considered to be statistically significant.

\section{Results}

Effects of administration of ethanol on sleep pattern

Sleep and PS latency. Figure 1 shows the effects of vehicle or ethanol on sleep and PS latencies. No significant alteration was observed in sleep latency; however, the $3.5 \mathrm{~g} / \mathrm{kg}$ ethanol group did show a significant increase in the PS latency compared with vehicle and $0.5 \mathrm{~g} / \mathrm{kg}$ ethanol groups $(P<0.01)$.

Total time of $P S$. Repeated measures ANOVA indicated a significant effect of treatments $[F(5,52)=3.73$; $P<0.006]$ and recording periods $[F(5,260)=40.8 ; P<0.001]$, but no significant interaction between these two factors $[F(25,260)$ 
$=1 ; \mathrm{P}=0.46]$. Thus, the results shown in Figure $2 \mathrm{~A}$ are related to the effects of acute ethanol administration on the duration of paradoxical sleep. These results were independent of the dose used. The dose-response curve showed a reduction in PS after the administration of 2.0 and $3.5 \mathrm{~g} / \mathrm{kg}$ ethanol compared with the vehicle group $(P<0.05$; Figure 2B). Within the first $2 \mathrm{~h}$ after ethanol administration, time of PS was reduced compared to all periods $(P<0.001$; Figure $2 \mathrm{~A}$ ) and a rebound effect was observed in all groups during the 6-12-h period after ethanol administration.

Sleep efficiency and total time of SWS. Significant increases occurred in sleep efficiency and SWS $[F(5,260)$ $=15.7 ; P<0.001$ and $F(25,260)=5.8 ; P=0.001]$ in the 612-h period after ethanol administration compared with the 0-2-h period. No significant effect was observed after ethanol administration on the sleep efficiency and SWS $[F(5,52)$ $=0.37 ; P=0.86$ and $F(5,52)=1.2 ; P=0.29]$ and interaction $[F(25,260)=1.1 ; P=0.31$ and $F(25,260)=1.4 ; P=0.11]$.
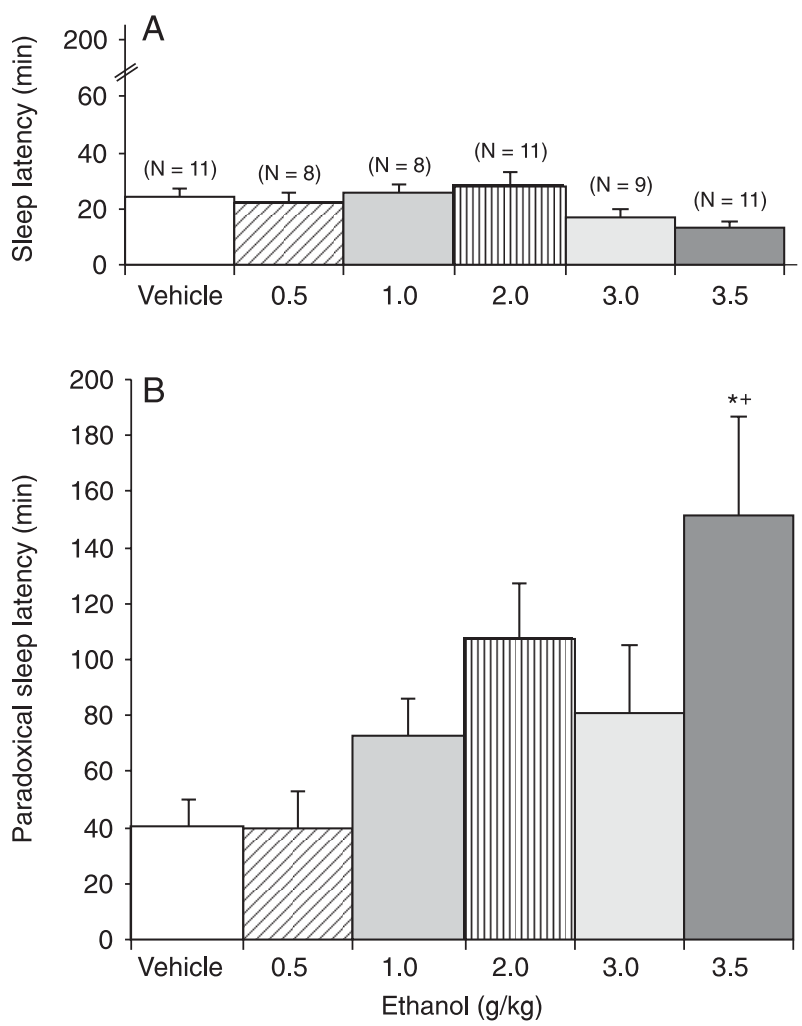

Figure 1. Effects of acute administration of ethanol on sleep (A) and paradoxical sleep latencies (B) determined by the time lag between the onset of recording and the first sleep period. Data are reported as means \pm SEM for $8-11$ rats per group. ${ }^{*} P<0.01$ compared to vehicle group, and ${ }^{+} \mathrm{P}<0.02$ compared to $0.5 \mathrm{~g} / \mathrm{kg}$ ethanol group (one-way ANOVA followed by the Tukey test).
Effects of concomitant administration of ethanolpilocarpine on the sleep pattern

Sleep and PS latency. Treatment with the muscarinic antagonist pilocarpine $(5$ and $10 \mathrm{mg} / \mathrm{kg}$ ) induced a significant increase in sleep latency compared to the saline and $2.5 \mathrm{mg} / \mathrm{kg}$ groups $[\mathrm{F}(3,60)=17.9 ; \mathrm{P}<0.001$; Figure 3]. Furthermore, a significant increase in PS latency was observed in the rats that received ethanol $(3.5 \mathrm{~g} / \mathrm{kg})$ and vehicle group $[F(1,60)=16.1 ; P<0.001]$

Total time of $P S$. Three-way ANOVA showed a significant effect of ethanol $[F(1,58)=11.1 ; P<0.001]$, recording period $[F(1,58)=114.6 ; P<0.001]$, and interaction $[F(1,58)$ $=12.8 ; P<0.001]$. No difference was observed after pilocarpine administration.

Effects of concomitant administration of ethanolatropine on the sleep pattern

Sleep latency and PS latency. No significant differ-
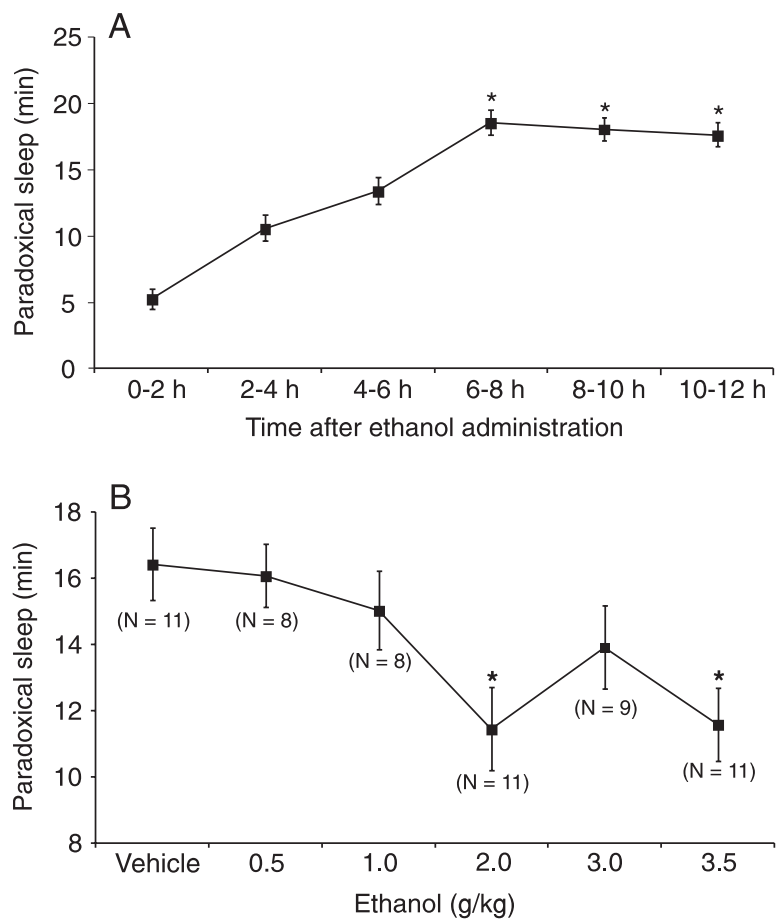

Figure 2. Effects of acute administration of ethanol on the duration of paradoxical sleep. $A$, Time after ethanol administration. $B$, Dose of ethanol. Data are reported as means \pm SEM for 8-11 rats/group. ${ }^{*} \mathrm{P}<0.05$ compared to vehicle group and $0-2 \mathrm{~h}$ (twoway ANOVA followed by the Tukey test). 

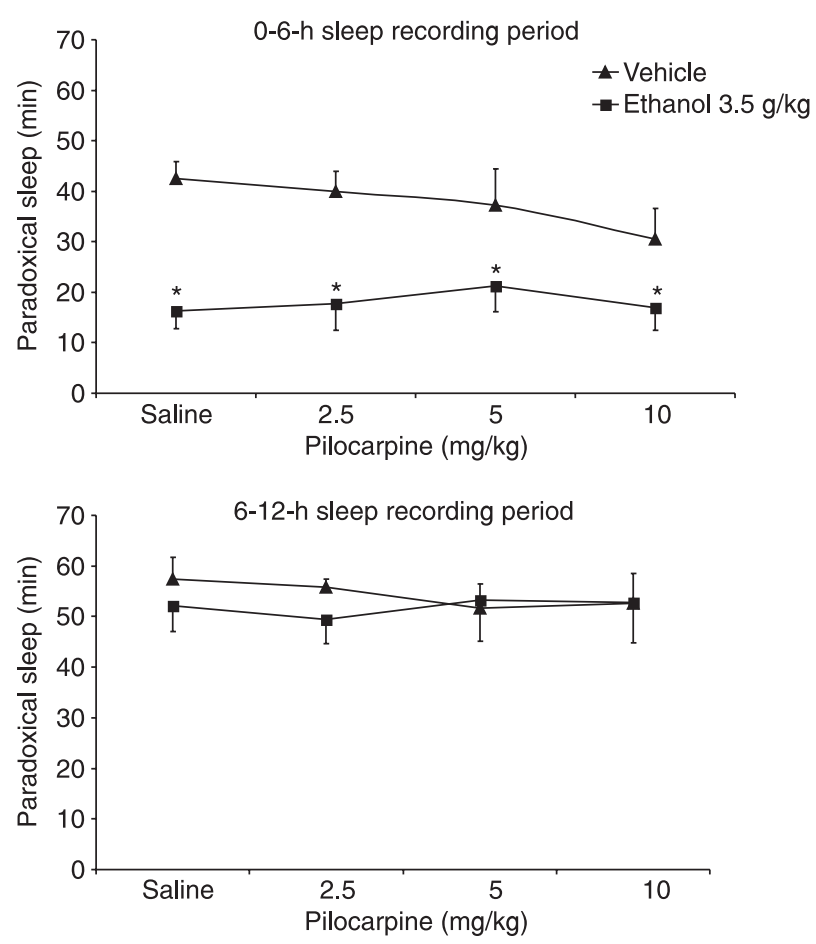

Figure 3. Effects of pilocarpine administration on the duration of paradoxical sleep suppressed by ethanol [saline or ethanol $(\mathrm{N}=$ 12 and 11$) ; 2.5 \mathrm{mg} / \mathrm{kg}$ pilocarpine and saline or ethanol $(\mathrm{N}=7$ and 8$) ; 5 \mathrm{mg} / \mathrm{kg}$ pilocarpine and saline or ethanol ( $\mathrm{N}=8$ and 11); $10 \mathrm{mg} / \mathrm{kg}$ pilocarpine and saline or ethanol ( $\mathrm{N}=5$ and 6$)]$. At 6:00 $\mathrm{h}$, each animal was given the appropriate dose of pilocarpine. One hour after injection, each animal was challenged with $3.5 \mathrm{~g} /$ $\mathrm{kg}$ ethanol. Data are reported as means \pm SEM. ${ }^{*} \mathrm{P}<0.05$ compared to ethanol group (three-way ANOVA followed by the Tukey test). ences were observed in sleep latency after atropine administration. There was a significant increase of PS latency in all treatments compared with the vehicle group (Table 1). Once again, PS latency was significantly increased after ethanol administration $[F(1,69)=20.6 ; P<0.001]$ and although atropine treatment displayed a similar increase compared with the ethanol group, PS latency was lower in the $10 \mathrm{mg} /$ $\mathrm{kg}$ atropine group compared to the 2.5 and $5.0 \mathrm{mg} / \mathrm{kg}$ groups $[\mathrm{F}(3,69)=16 ; \mathrm{P}<0.001]$. There was no interaction between the ethanol and atropine treatments.

Total time of PS. Three-way ANOVA showed that there was a difference in PS time between drug, ethanol and recording periods; this was concomitant to a significant interaction among these factors $[F(3,69)=3.7 ; P<0.02 ;$ Table 1]. Total time of $\mathrm{PS}$ was markedly reduced after ethanol and/or atropine treatments $(P<0.001)$ as all groups showed reduced PS in the 0-6-h interval compared to the vehicle, except for the $10 \mathrm{mg} / \mathrm{kg}$ atropine-vehicle group. A rebound effect was observed in all groups
Table 1. Effect of atropine on sleep, paradoxical sleep latencies and duration of paradoxical sleep suppressed by ethanol.

\begin{tabular}{lcccc}
\hline & Vehicle & Ethanol & Vehicle & Ethanol \\
\hline Sleep latency & & & & \\
Saline & $24.6 \pm 3.7$ & $13.5 \pm 2.6$ & & \\
Atropine $(2.5 \mathrm{mg} / \mathrm{kg})$ & $29.9 \pm 5.0$ & $16.5 \pm 2.8$ & & \\
Atropine $(5 \mathrm{mg} / \mathrm{kg})$ & $31.9 \pm 13.5$ & $19.7 \pm 7.6$ & & \\
Atropine $(10 \mathrm{mg} / \mathrm{kg})$ & $25.3 \pm 5.3$ & $9.9 \pm 1.8$ & & \\
Paradoxical sleep latency & & & & \\
Saline & $40.3 \pm 10.7$ & $150.9 \pm 36.5^{*}$ & & \\
Atropine $(2.5 \mathrm{mg} / \mathrm{kg})$ & $204.4 \pm 29.6^{*}$ & $253.6 \pm 39.7^{*}$ & & \\
Atropine $(5 \mathrm{mg} / \mathrm{kg})$ & $202.2 \pm 6.9^{*}$ & $295.9 \pm 39.9^{*}$ & & \\
Atropine $(10 \mathrm{mg} / \mathrm{kg})$ & $91.7 \pm 14.1^{*+}$ & $215.3 \pm 43.1^{*}$ & & \\
Paradoxical sleep & & $0-6-\mathrm{h}$ period & & \\
Saline & $42.5 \pm 3.3$ & $16.4 \pm 3.6^{*}$ & $57.4 \pm 4.4$ & $52 . \mathrm{h}$ period \\
Atropine $(2.5 \mathrm{mg} / \mathrm{kg})$ & $12.6 \pm 3.5^{*}$ & $7.4 \pm 2.3^{*}$ & $52.6 \pm 5.5^{* *}$ & $41.1 \pm 5.8^{* *}$ \\
Atropine $(5 \mathrm{mg} / \mathrm{kg})$ & $14.5 \pm 2.7^{*}$ & $4.8 \pm 1.9^{*}$ & $63.4 \pm 5.7^{* *}$ & $44.7 \pm 4.0^{* *}$ \\
Atropine $(10 \mathrm{mg} / \mathrm{kg})$ & $31.2 \pm 3.3$ & $12.2 \pm 3.2^{*}$ & $60.3 \pm 3.3^{* *}$ & $60.7 \pm 4.8^{* *}$ \\
\hline
\end{tabular}

Data are reported as mean \pm SEM. At $6 \mathrm{~h}$, each animal was given an appropriate dose of atropine. One hour after injection, each animal was challenged with $3.5 \mathrm{~g} / \mathrm{kg}$ ethanol. Saline $(N=12)$ or ethanol $(N=11) ; 2.5 \mathrm{mg} / \mathrm{kg}$ atropine and saline or ethanol $(\mathrm{N}=10) ; 5$ $\mathrm{mg} / \mathrm{kg}$ atropine and saline or ethanol $(\mathrm{N}=8) ; 10 \mathrm{mg} / \mathrm{kg}$ atropine and saline or ethanol $(\mathrm{N}$ $=9)$.

${ }^{*} \mathrm{P}<0.05$ compared to saline-vehicle group; ${ }^{+} \mathrm{P}<0.05$ compared to 2.5 or $5 \mathrm{mg} / \mathrm{kg}$ atropine and ethanol groups; ${ }^{*} \mathrm{P}<0.05$ compared to 6-12-h period (two-way ANOVA for sleep and paradoxical sleep latencies and three-way ANOVA for paradoxical sleep followed by the Tukey test). 
in the second interval (6-12 h).

\section{Discussion}

The results reported here demonstrated a significant dose effect of ethanol-induced suppression of PS in rats. In the first ECoG recording hour, the dose of $3.5 \mathrm{~g} / \mathrm{kg}$ ethanol suppressed PS in all $(\mathrm{N}=11)$ rats tested. In addition, at all quantities of ethanol tested, there was a significant increase in PS in the 6th hour after ethanol administration. The adoption of 2-h intervals between scoring periods in this investigation clearly showed the longitudinal effect of ethanol on sleep architecture in all sleep parameters in a manner suggesting that these alterations occur differently for each parameter. In order to investigate the contribution of the cholinergic system, a muscarinic agonist (pilocarpine) and an antagonist (atropine) were administered $1 \mathrm{~h}$ prior to ethanol. There was a significant reduction of PS during the first 6 recording hours with 2.5 and $5.0 \mathrm{mg} / \mathrm{kg}$ atropine, and these significantly reduced PS. Pilocarpine, in turn, did not statistically alter the sleep architecture as expected.

The effects of ethanol on sleep architecture have been described in the literature for both humans and animal experimental paradigms. Dose-dependent inhibition of PS in humans after acute administration of $0.9 \mathrm{~g} / \mathrm{kg}$ ethanol was reported in healthy volunteers, whereas SWS remained unaltered (1). This finding indicates that ethanol specifically modifies PS. A decrease of PS with a possible rebound during the second half of the night (20) is a frequent sleep disturbance evaluated by various investigators. Since a dose-related reduction of PS following ethanol administration is a common observation in normal nonalcoholic subjects, the effects observed in animals appear to be similar to those in normal human subjects.

In rodents, acute ethanol has been shown to reduce sleep latency (4), increase SWS (5), and decrease PS in a dose-dependent manner (7). The reduction in PS did not reach statistical significance in an acute oral administration protocol (21), nor did it result in statistical changes in the time spent in sleep following intragastric infusion of a low ethanol dose in alcohol-preferring and alcoholnonpreferring rats (22). The route of administration seems to provide an additional variable in the sleep pattern. Inhalation, parenteral, oral (gastric), or intracerebroventricular administration causes distinct results $(21,22)$, and a wide dose range also makes the scenario more complex. These observations further reinforce the concept that the effects of ethanol on sleep parameters are dependent on the susceptibility of ethanol-preferring strains and the normal vigilance state of the animal (21). Differences were found when the drug was administered at different times in the rat circadian cycle (21).

More studies are needed to better understand the neurobiological mechanisms underlying the reduction or abolishment in PS following acute ethanol exposure. We speculate that these consistent effects may be mediated by the effect that ethanol has on either the steady-state levels or turnover rates of one or more neurotransmitters. This substance interacts with several neurotransmitters within the central nervous system, including $\gamma$-aminobutyric acid (GABA), serotonin, catecholamines, and opiates (23). Although many studies have demonstrated the effects of ethanol on the central cholinergic system, these studies reveal some conflicting findings. The mechanism responsible for ethanol-induced PS inhibition suggests that acute doses of ethanol cause inhibitory effects on the central cholinergic pathways (15,24-26). It has also been suggested that cholinergic neurons are a primary target for ethanol in the brain $(27,28)$. Such conjecture could be due to in vitro and in vivo observations of the reduction of acetylcholine release $(14,15,24-26,29)$, which results in a decrease of cholinergic activity since cholinergic agonists induce (30) and antagonists block $(12,31)$ PS. Thus, ethanol could inhibit glutamatergic neurons, reducing acetylcholine concentrations. Recently, an increase of acetylcholine transmission by systemic ethanol acting on cholinergic dendrites and cell bodies (32) showed that the neurochemical consequences of ethanol still warrant additional studies.

In the present study, administration of atropine (+ vehicle) and atropine treatment prior to ethanol exposure caused a reduction in PS compared with the vehicle group. Pilocarpine, in turn, did not modify PS in the three doses tested. The reasons for the absence of effects on PS by pilocarpine may be attributed to the distinct modulation effect of agonist vs antagonist upon ethanol suppression of PS on the central nervous system. Much data have been shown in the literature describing the effects of ethanol on biological substrates. Clinical sleep studies are hampered by a reduced number of subjects available for experimentation; however, this scenario is further compounded by hindrance in observing the effects of increasing doses of ethanol in healthy volunteers. In light of these complications, animal models have permitted the experimental control necessary in the investigation of the long-term effects of ethanol and the dose-response effect on sleep architecture.

In conclusion, this study presents data concerning the effects of ethanol on sleep and suggests that the cholinergic system interacts with ethanol and sleep in rodents. 


\section{Acknowledgments}

We are grateful to Prof. Dr. Marcus Vinícius Chrysóstomo Baldo for statistical assistance. The authors gratefully acknowledge the invaluable assistance of Waldemarks Leite, Tathiana Alvarenga, Marilde Costa, and Tomé Pimentel.

\section{References}

1. Lobo LL, Tufik S. Effects of alcohol on sleep parameters of sleep-deprived healthy volunteers. Sleep 1997; 20: 52-59.

2. Roehrs T, Roth T. Sleep, sleepiness, and alcohol use. Alcohol Res Health 2001; 25: 101-109.

3. Tanigawa T, Tachibana N, Yamagishi K, Muraki I, Umesawa $\mathrm{M}$, Shimamoto $\mathrm{T}$, et al. Usual alcohol consumption and arterial oxygen desaturation during sleep. JAMA 2004; 292: 923-925.

4. Hill SY, Reyes RB, Kupfer DJ. Alteration of ethanol-induced sleep latency by physostigmine in animals. Subst Alcohol Actions Misuse 1982; 3: 101-105.

5. Branchey $\mathrm{MH}$, Begleiter $\mathrm{H}$, Kissin $\mathrm{B}$. The effects of various doses of alcohol on sleep in the rat. Commun Behav Biol 1976; 5: 75-79.

6. Ghosh TK, Copeland RL Jr, Pradhan SN. Effects of ethanol inhalation on EEG in rats. Pharmacol Biochem Behav 1991; 38: 293-297.

7. Mendelson WB, Hill SY. Effects of the acute administration of ethanol on the sleep of the rat: a dose-response study. Pharmacol Biochem Behav 1978; 8: 723-726.

8. Jones BE. Modulation of cortical activation and behavioral arousal by cholinergic and orexinergic systems. Ann NY Acad Sci 2008; 1129: 26-34.

9. Steriade M, McCarley R. REM sleep as a biological rhythm. In: Steriade M, McCarley R (Editors), Brainstem control of wakefulness and sleep. New York: Plenum; 1990. p 363-393.

10. Cui R, Suemaru K, Li B, Araki H. The effects of atropine on changes in the sleep patterns induced by psychological stress in rats. Eur J Pharmacol 2008; 579: 153-159.

11. Baghdoyan HA, Monaco AP, Rodrigo-Angulo ML, Assens F, McCarley RW, Hobson JA. Microinjection of neostigmine into the pontine reticular formation of cats enhances desynchronized sleep signs. J Pharmacol Exp Ther 1984; 231: 173-180.

12. Shiromani PJ, Fishbein W. Continuous pontine cholinergic microinfusion via mini-pump induces sustained alterations in rapid eye movement (REM) sleep. Pharmacol Biochem Behav 1986; 25: 1253-1261.

13. Jones BE. Paradoxical sleep and its chemical/structural substrates in the brain. Neuroscience 1991; 40: 637-656.

14. Kalant $H$, Israel $Y$, Mahon MA. The effect of ethanol on acetylcholine synthesis, release, and degradation in brain. Can J Physiol Pharmacol 1967; 45: 172-176.

15. Kalant $\mathrm{H}$, Grose W. Effects of ethanol and pentobarbital on release of acetylcholine from cerebral cortex slices. J Pharmacol Exp Ther 1967; 158: 386-393.

16. Andersen ML, D'Almeida V, Ko GM, Kawakami R, Martins PJF, Magalhães LE, et al. Experimental procedure. In: UNIFESP (Editor), Ethical and practical principles of the use of laboratory animals. São Paulo: 2004. p 45-69.

17. Timo-laria C, Negrao N, Schmidek WR, Hoshino K, Lobato de Menezes CE, Leme da Rocha T. Phases and states of sleep in the rat. Physiol Behav 1970; 5: 1057-1062.

18. Andersen ML, Tufik S. Sleep patterns over 21-day period in rats with chronic constriction of sciatic nerve. Brain Res 2003; 984: 84-92.

19. Madsen BW, Rossi L. Sleep and Michaelis-Menten elimination of ethanol. Clin Pharmacol Ther 1980; 27: 114-119.

20. Rundell OH, Lester BK, Griffiths WJ, Williams HL. Alcohol and sleep in young adults. Psychopharmacologia 1972; 26: 201-218.

21. Kubota T, De A, Brown RA, Simasko SM, Krueger JM. Diurnal effects of acute and chronic administration of ethanol on sleep in rats. Alcohol Clin Exp Res 2002; 26: 1153-1161.

22. Morzorati S, Lamishaw B, Lumeng L, Li TK, Bemis K, Clemens J. Effect of low dose ethanol on the EEG of alcohol-preferring and -nonpreferring rats. Brain Res Bull 1988; 21: 101-104.

23. Koob GF, Weiss F. Neuropharmacology of cocaine and ethanol dependence. Recent Dev Alcohol 1992; 10: 201-233.

24. Erickson CK, Graham DT. Alteration of cortical and reticular acetylcholine release by ethanol in vivo. J Pharmacol Exp Ther 1973; 185: 583-593

25. Carmichael FJ, Israel Y. Effects of ethanol on neurotransmitter release by rat brain cortical. J Pharmacol Exp Ther 1975; 193: 824-834

26. Morgan EP, Phillis JW. The effects of ethanol on acetylcholine release from the brain of unanesthetized cats. Gen Pharmacol 1975; 6: 281-284.

27. Arendt $\mathrm{T}$, Bigl $\mathrm{V}$, Arendt $\mathrm{A}$, Tennstedt $\mathrm{A}$. Loss of neurons in the nucleus basalis of Meynert in Alzheimer's disease, paralysis agitans and Korsakoff's disease. Acta Neuropathol 1983; 61: 101-108.

28. Arendt $\mathrm{T}$, Allen $\mathrm{Y}$, Marchbanks RM, Schugens MM, Sinden $\mathrm{J}$, Lantos PL, et al. Cholinergic system and memory in the rat: effects of chronic ethanol, embryonic basal forebrain brain transplants and excitotoxic lesions of cholinergic basal forebrain projection system. Neuroscience 1989; 33: 435-462.

29. Sanna E, Dildy-Mayfield JE, Harris RA. Ethanol inhibits the function of 5-hydroxytryptamine type 1c and muscarinic M1 G protein-linked receptors in Xenopus oocytes expressing brain mRNA: role of protein kinase C. Mol Pharmacol 1994; 45: 1004-1012.

30. Hobson JA, Goldberg M, Vivaldi E, Riew D. Enhancement of desynchronized sleep signs after pontine microinjection of the muscarinic agonist bethanechol. Brain Res 1983; 275: $127-136$.

31. Szymusiak R, Danowski J, McGinty D. REM sleep-suppressing effects of atropine in cats vary with environmental temperature. Brain Res 1994; 636: 115-118.

32. Stancampiano R, Carta M, Cocco S, Curreli R, Rossetti ZL, Fadda F. Biphasic effects of ethanol on acetylcholine release in the rat prefrontal cortex. Brain Res 2004; 997: 128-132. 